\title{
A ILUSTRAÇÃO DE LIVROS INFANTIS - UMA RETROSPECTIVA HISTÓRICA ${ }^{1}$
}

Neli Klix Freitas², Anelise Zimmermann ${ }^{3}$

Palavras-chave: ilustração, livro infantil, ilustrador

Resumo: O presente estudo visa destacar a relação entre leitor e livro infantil a partir de uma retrospectiva histórica da ilustração na literatura, considerando o seu surgimento, ideologias presentes e modificações através dos tempos, buscando, com isso, uma melhor compreensão da participação do livro na infância, além de valorizar o ilustrador, lembrando que os livros infantis são resultado da combinação de texto e imagem.

\section{Introdução}

Para compreender-se a relação entre os livros infantis ilustrados e a criança, considera-se indispensável o estudo do histórico da ilustração e do livro, visando destacar o momento em que ambos se encontram e passam a ser desenvolvidos especificamente para o leitor infantil, com características específicas e objetivos diversos que vão se modificando dentro de cada período. O estudo dessas modificações, relacionado principalmente aos acontecimentos sociais, econômicos e tecnológicos pelos quais a sociedade tem passado nos permitem melhor entender o valor atribuído ao livro na infância, tanto no passado, quanto no presente.

\section{A ilustração: dos pergaminhos aos websites}

No livro Alice no País das Maravilhas (CARROL, 2001), a personagem principal, tenta acompanhar a leitura de um livro com sua irmã, mas se sente entediada pois o livro "não tinha figuras nem diálogos; e 'para que serve um livro', pensou Alice, 'sem figuras ou diálogos'?" (CARROLL, 2001, p. 37).

\footnotetext{
${ }^{1}$ Projeto de Pesquisa de Mestrado em Arte Visuais - CEART - UDESC.

${ }^{2}$ Orientadora, Doutora em Psicologia, Professora nos Cursos de Graduação e de Mestrado em Artes Visuais do Centro de Artes (CEART - UDESC).

${ }^{3}$ Acadêmica do Curso de Mestrado em Artes Visuais do Centro de Artes (CEART - UDESC).

${ }^{4}$ Tradução nossa. "(...) it had no pictures or conversations in it; 'and what is the use of book', thought Alice,
} 
Essas figuras, das quais Alice fala, são as ilustrações do livro, que, principalmente na infância, instigam a curiosidade e convidam à leitura. Para a Associação dos Designers Gráficos (2000, p.59) uma imagem é considerada ilustração quando seu objetivo for "corroborar ou exemplificar o conteúdo de um texto de livro, jornal, revista ou qualquer outro tipo de publicação". Completando essa definição, a ilustração pode ser também uma imagem que substitui um texto, que o amplia, que adiciona a ele informações, ou que o questiona.

Conforme estudos de Dalley (1982) oficialmente não se tem exatidão de quando datam as primeiras ilustrações, principalmente devido às diferentes definições que o termo apresenta. Para alguns autores, tanto a ilustração, como a escrita, possuem suas origens na pré-história, a partir das inscrições rupestres.

As ilustrações consideradas documentais, ou seja, que tinham como objetivo registrar acontecimentos da época, como por exemplo, a construção dos monumentos, aparecem no Antigo Egito. É também desse período os primeiros pergaminhos ilustrados.

Durante o período das civilizações grega e romana é a função descritiva e objetiva da ilustração que prevalece, consolidando-se dentro das áreas das ciências, como na topografia, medicina e arquitetura.

Na Idade Média, a ilustração aparece a serviço da religião, assumindo uma nova função: a de levar os ideais da igreja à grande parte da população analfabeta. Um exemplo desse período é a Bíblia Pauperum, reproduzida através da xilogravura.

Com o retorno à cultura greco-romana e consequentemente, ao predomínio da razão e da ciência, durante o Renascimento, as ilustrações aparecem fortemente voltadas ao desenho técnico. Leonardo da Vinci é considerado o mais importante ilustrador técnico dessa época. Surge nesse período também, a chamada ilustração satírica.

À medida que novas técnicas de impressão surgem, como a água-forte, a xilografia em cor, a litografia (1796) e a cromolitografia (1851), a ilustração ganha maior espaço dentro da área editorial. Outro importante invento do século XIX é a fotografia (1839) que, por seu realismo, fez com que ilustradores se voltassem mais ao estímulo à imaginação do que ao realismo.

No início do século XX surge no ocidente a serigrafia, são feitos avanços consideráveis na área de produção de tintas, além do desenvolvimento da impressão em meio tom, aumentando substancialmente as possibilidades técnicas de reprodução ao 'without pictures or conversation?' ". 
ilustrador. A ilustração passa então a ser reconhecida como arte comercial.

Nos últimos anos, entre as mais recente e importantes inovações na área estão a introdução e o aperfeiçoamento da computação gráfica, além do surgimento das mídias digitais, como jornais, livros, revistas eletrônicas e websites, abrindo novos campos de atuação para ilustradores.

\section{O livro infantil: das fábulas às ficções científicas}

Conforme pesquisas de Lajolo e Zilberman (2006) as primeiras publicações de livros apareceram no século XV, porém, é somente no século XVIII que surgem os livros especificamente voltados para a criança. Até então, obras como as Fábulas de La Fontaine (1668 e 1694) e os Contos da Mamãe Gansa de Charles Perrault (1697), atualmente associados ao gênero infantil, haviam sido publicados visando o público em geral. Por serem obras originárias de histórias contadas pelo povo, não se enquadravam dentro dos parâmetros exigidos pelas Academia de Letras, o que dificultava o interesse dos escritores pelo gênero. É após o sucesso das obras de Perrault que a literatura infantil adquire espaço, caracterizada principalmente pelos contos de fadas.

Apesar das publicações francesas de La Fontaine e Perrault é na Inglaterra que a literatura infantil, como produto de consumo, ganha importância, fortalecida pelo forte comércio do país, abundância de matéria-prima e, principalmente, seu desenvolvimento com a Revolução Industrial. Este é o período do crescimento das cidades e consolidação da burguesia. Entre as instituições que garantem o seu fortalecimento está a família. Cada membro assume um papel específico na sociedade, até mesmo a criança, "motivando o aparecimento de objetos industrializados (o brinquedo) e culturais (o livro) ou novos ramos da ciência (a psicologia infantil, a pedagogia ou a pediatria)" (LAJOLO E ZILBERMAN, 2006, p. 17). São associadas à criança características como a fragilidade e a dependência, cabendo à escola prepará-la para a vida adulta, que passa a ter frequiência obrigatória.

Considerando a expansão da industrialização e comércio nesse período histórico, o livro infantil surge com características de produto, pensando-se num consumo. Para tanto, era necessário a alfabetização do seu público. Daí decorre a relação dos livros com a escola, fazendo com que muitas publicações adotassem uma postura bastante pedagógica.

Destacam-se nesse século as publicações adaptadas de clássicos ao gênero infantil, 
como Robinson Crusoé (1717) de Daniel Defoe e Viagens de Gulliver (1726) de Jonathan Swiff.

No início do século XIX, surgem na Alemanha, as obras dos irmãos Grimm, (1812), feitas a partir de adaptações de histórias folclóricas populares. Entre alguns dos seus contos estão: A Bela Adormecida, Os sete anões e a Branca de Neve, Chapeuzinho Vermelho, Joãozinho e Maria (1825). São também do mesmo século as publicações de Hans Christian Andersen, na Dinamarca, com os contos O Patinho Feio, A roupa nova do imperador (1835-1842), entre muitos outros.

Como apresentado por Lajolo e Zilberman (2006) a partir de então repetem-se alguns temas que conquistaram a predileção dos leitores. São eles: as histórias fantásticas, como em Alice no País das Maravilhas (1863) de Lewis Carrol; jovens desbravadores vivendo aventuras em lugares exóticos, como Cinco Semanas num balão, (1863) de Jules Verne; e histórias do cotidiano infantil como As Meninas Exemplares (1857) da Condessa de Ségur. Com isso torna-se consolidado este gênero literário na Europa, aumentando, a cada ano, o número de produções, exportando-se muitos títulos a outros continentes. É assim que a literatura infantil chega ao Brasil, através de produções européias traduzidas. Somente no século XX é que aparece no país uma literatura, dentre essa categoria, que pode ser chamada de brasileira.

Assim como nos outros países, o livro no Brasil também surge numa relação com a industrialização, o comércio, a urbanização e a propagação da escola como instituição, Alguns exemplos de obras são: Contos Infantis (1886) de Júlia Lopes de Almeida e Adelino Lopes Vieira e Contos Pátrios (1904) de Olavo Bilac e Coelho Neto. Nessa época, prevalecem nos livros, valores como o patriotismo, o civismo, a brasilidade, o moralismo, a obediência, a exaltação à natureza, além de temas relacionados ao folclore brasileiro.

Em 1912 Monteiro Lobato publica Narizinho Arrebitado e a partir de então passa a se dedicar a esse gênero literário marcando para sempre a história da literatura no país.

Posteriormente surgem e se fortalecem outros nomes como José Lins do Rego, Érico Veríssimo e Graciliano Ramos, falando de temas até então inusitados na literatura infantil.

Nas décadas de 30 e 40, período marcado pelo Estado Novo e pela ditadura, ocorrem diversas reformas na área da educação e prevalece a preocupação na formação da criança como cidadã. Os livros que remetem à fantasia passam a ser considerados inadequados à infância. Em 1934 o Ensino Fundamental no Brasil torna-se finalmente 
obrigatório. (RADINO, 2003).

Os anos 50 são marcados pelos avanços tecnológicos e o advento dos meios de comunicação audiovisuais. Acontece a massificação da imagem, levando ao que Radino (2003, p. 107) considera uma "crise na leitura".

Já, a década de 70, é caracterizada por um grande salto de qualidade e criatividade, com inovações no gênero infantil, assumindo finalmente uma postura crítica. "Valoriza-se, neste momento, o espírito questionador, lúdico, irreverente e bem-humorado" (ibid, p. 108). São alguns títulos dessa nova fase: Bisa Bia Bisa Bel e História do Contrário de Ana Maria Machado; A Fada que tinha idéias, de Fernanda Lopes de Almeida e A Bolsa Amarela, de Lygia Bojunga Nunes.

Os temas abordados nos livros infantis também se ampliam, aparecendo as histórias policiais e as ficções científicas, ambas associadas ao cenário urbano contemporâneo: "mistérios a serem resolvidos e a manipulação de engenhos e fórmulas são atributos do homem urbano, mesmo quando reduzido à faixa etária de uma criança. (...) se originam grandes inventos e superpoderes" (LAJOLO e ZILBERMAN, 2006, p. 161).

Já nos últimos anos, o imaginário passa a ser bastante explorado, através de histórias baseadas em temas tanto universais como regionais, como elementos de nosso folclore, ocupando espaço de destaque dentro da literatura. "(...) após ter conquistado a duras penas o direito de falar com realismo e sem retoques da realidade histórica, e ao mesmo tempo que redescobre as fontes do fantástico e imaginário, a literatura infantil contempla-se a si mesma em seus textos" ( ibid, p. 161).

\section{O livro infantil ilustrado: das cartilhas escolares aos livros de imagens}

Os livros religiosos, as cartilhas escolares, principalmente as gramáticas, alfabetos (hornbooks) e enciclopédias com imagens são considerados, por muitos, os precursores do livro infantil ilustrado. Nesse período são raros os ilustradores que assinavam os seus trabalhos, permanecendo, na maioria das vezes, no anonimato. Além disso, à participação de diferentes "gravadores" (profissionais responsáveis pela reprodução dos originais nas matrizes de impressão) em uma mesma obra dificulta ainda mais a identificação de autoria. Um exemplo dos quais se tem conhecimento é o Orbis Sensualium Pictus (O livro visível em imagens, 1658) de John Amos Comenius (BURLINGHAM, 2007). 
No final do século XVII (1697) são publicados os contos de fadas de Perrault, ilustrados por Gustave Doré, com imagens em preto e branco caracterizadas principalmente pela grande riqueza de detalhes.

Em contrapartida às fábulas, aparecem publicações de caráter moralista e religioso como Songs of Innocence do Illuminated Book (1789), de Willian Blake, que inovou no gênero ao trabalhar imagem e texto de forma integrada (BLAKE, 2003).

Já no século XIX, na Inglaterra, destacam-se as traduções dos Irmãos Grimm, German Popular Stories ilustradas por George Cruikshank (1823), com ilustrações carregadas de humor e ritmo (BLAKE, 2003).

Outra importante publicação deste mesmo século é Alice no País das Maravilhas (1865), escrita por Lewis Carrol e ilustrada por John Tenniel. Até hoje, suas ilustrações da obra são as mais memoráveis, apesar do grande número de reedições feitas por diferentes ilustradores.

In Fairyland (1870), livro ilustrado por Richard Doyle e escrito por Willian Allingham, também obteve grande sucesso entre o público infantil por suas imagens povoadas por duendes e fadas.

É também deste século um grande número de publicações elaboradas com efeitos de рор-up (ilustrações tridimensionais), cortes especiais, peças para serem recortadas, livros que se tornavam cenários, bonecas de papel e os chamados harlequinade (ilustrações em abas móveis que imagens escondidas). Um dos principais ilustradores desse gênero foi Lothar Meggendorfer. Com a I Guerra Mundial esse tipo de livro deixou de ser publicado em função de seu alto custo e dificuldades de importação (BURLINGHAM, 2007).

Já, carregando as imagens de grande humor, destacam-se as obras ilustradas por Walter Crane. Uma de suas publicações, The Frog Prince (1874) salienta-se justamente por trazer certa comicidade às cenas mais pesadas, além da forte presença da bidimensionalidade nas imagens. Outra importante ilustradora da época, Kate Greenaway, obteve grande sucesso por representar principalmente crianças em cenas bucólicas, o que cativou o público infantil (Under the Window-1878).

Citado por Benjamim (1984) como importantes publicações ilustradas no mesmo século estão as obras dos irmãos Grimm ilustradas Peter Lyser, como o Livro das Fábulas (1827).

No início do século XX, destacam-se as obras Beatrix Potter, que inovou ao 
associar comportamentos humanos a animais como em The Peter Rabbit, além de demonstrar grande preocupação com as características físicas do livro, de forma a ser facilmente manuseável pelas crianças. Outro nome importante nesse período é E. H. Shepard, criador do até hoje famoso ursinho Pooh. Este personagem chama a atenção por ser, não apenas um urso, mas também, um bicho de pelúcia que em alguns momentos deixa de ser um brinquedo e ganha vida (BLAKE, 2003).

Também merecem destaque as diversas reedições de clássicos, como as histórias dos Irmãos Grimm, ilustradas por Arthur Rendak, Edmund Dulac e Key Nielsen, as quais apresentam forte influência do estilo Art Nouveau e grande apelo à fantasia e ao imaginário.

O final do século é marcado pela grande variedade de estilos de ilustrações, estimulada pelo desenvolvimento tecnológico na área editorial. No Brasil, é apenas nesse período que a ilustração começa a receber atenção dentro do livro infantil e nomes de ilustradores passam finalmente a serem conhecidos, como Eva Furnari, Elvira Vigna, Rui de Oliveira, Roger Mello, Graça Lima, Ciça Fittipaldi, Nelson Cruz, entre outros.

Cada vez mais ilustradores passam a escrever seus próprios livros, como Ziraldo, com a célebre publicação de $\mathrm{O}$ Menino Maluquinho, entre muitos outros, além do aparecimento dos livros de imagens, ou seja, livros sem texto, como o Cântico dos Cânticos de Ângela Lago, mostrando que é possível construir uma história usando apenas ilustrações.

Atualmente destacam-se, mundialmente, entre tantos, alguns nomes como Lauren Child, cujos protagonistas de seus livros, Charlie e Lola, acabaram virando personagens de desenhos animados, Quentin Blake, que utiliza muito mais a ilustração do que o texto escrito para contar suas histórias, David Roberts (ilustrador) que, juntamente com seu irmão, Lynn Roberts (escritor) adapta clássicos da literatura aos tempos atuais e Babette Cole, trazendo temas como homossexualismo e a morte para os livros infantis.

No Brasil, além nos nomes de ilustradores já mencionados, pode-se citar Mariana Massarani, Elizabeth Teixeira e André Neves, que têm conquistado o público infantil por explorarem o imaginário da criança através do inusitado.

\section{Considerações Finais}

O estudo do histórico da ilustração e do livro infantil nos permite compreender a 
visão tida pelo adulto do universo da criança através dos tempos, como se deram as modificações dentro dessa área e em função de que, auxiliando também na identificação das ideologias presentes em muitos obras e no entendimento da relação que entre leitor e livro nos dias de hoje. Além disso, tal pesquisa visa valorizar o trabalho e a participação do ilustrador na elaboração e desenvolvimento do livro infantil, lembrando que este é o resultado da combinação entre texto e imagem. É, geralmente, o bom entrosamento entre ambos que faz as históricas contadas nos livros ganharem vida. "Frente ao livro ilustrado a criança (...) vence a parede ilusória da superfície e, esgueirando-se entre tapetes e bastidores coloridos, penetra em um palco onde o conto de fadas vive" (BENJAMIN, 1984, p. 55).

\section{Referências}

ADG. ABC da ADG. Glossário de termos e verbetes utilizado em design gráfico. São Paulo: Melhoramentos, 2000.

BENJAMIM, Walter. Reflexões: a criança, o brinquedo, a educação. São Paulo: Summus, 1984.

BLAKE, Quentin (selec.). Magic Pencil. Children's book illustration today. London: The British Library, 2003.

BURLINGHAM, Cynthia. Picturing childhood. The evolution of the illustrated children's book. Disponível em: <http//: www.library.ucla.edu/special/childhood/pictur.htm> Acessado em: 28 mai. 2007.

CARROL, Lewis. Alice in wonderland. London: Wordsworth, 2001.

LAJOLO, Marisa e ZILBERMAN, Regina. Literatura infantil brasileira. Histórias e Histórias. 6. ed. São Paulo: Ática, 2006.

RADINO, Glória. Contos de fadas e realidade psíquica. A importância da fantasia no desenvolvimento. São Paulo: Casa do Psicólogo, 2003. 